\title{
An NHANES Analysis of 2005 - 2006 Data Examining the Relationship Between Diabetes Mellitus and Vitamin C Ingestion
}

\author{
Daniel Fischman ${ }^{\mathrm{a}}$, Venkata Subhash Gorrepati ${ }^{\mathrm{b}, \mathrm{c}}$, Pramil Cheriyath ${ }^{\mathrm{a}}$
}

\begin{abstract}
Background: Diabetes mellitus (DM) is one of the most common diseases afflicting the United States (U.S.) population. Vitamin C (Ascorbic acid) is considered to be one of the most potent antioxidants present in the body. Thus, we present the results of our epidemiologic analysis of whether Vitamin $\mathrm{C}$ ingestion is related to the development of diabetes mellitus.
\end{abstract}

Methods: For the purpose of our study, we examined National Health and Nutrition Examination Survey (NHANES) data collected between 2005 and 2006. Of 10,348 participants who had data collected during this two-year period, 4979 did not meet any exclusion criteria, and were included in our data analysis. We performed a multivariate logistic regression to find out whether plasma levels of vitamin $\mathrm{C}$ were correlated with the development of diabetes.

Results: The unadjusted odds ratios of having diabetes in the four quartiles of Vitamin C starting from lowest to highest were 1, 0.87 (95\% CI of $0.67-1.13), 0.62$ (95\% CI of $0.50-0.78)$ and $0.45(95 \%$ CI of $0.359-0.557)$, respectively. When the analysis was adjusted for risk factors the odds ratios still showed a dose-response relation with odds ratios of $1,0.79$ (95\% CI of 0.6-1.04), 0.58 (95\% CI of $0.45-0.76)$ and 0.53 (95\% CI of $0.43-0.63)$, respectively.

Manuscript accepted for publication February 22, 2012

${ }^{a}$ Attending Physician and Faculty, Pinnacle Health/Drexel University, Harrisburg Hospital, 111 S Front Street, Harrisburg, PA, 17101, USA

${ }^{\mathrm{b}}$ Resident Physician, Pinnacle Health/Harrisburg Hospital, 111 S Front Street, Harrisburg, PA, 17101, USA

${ }^{\mathrm{c} C o r r e s p o n d i n g ~ a u t h o r: ~ V e n k a t a ~ S u b h a s h ~ G o r r e p a t i . ~}$

Email: venkatasubhash@gmail.com

doi:10.4021/jem88e
Conclusions: Our study supports the hypothesis that higher plasma levels of Vitamin C levels are protective against the development of Diabetes Mellitus. Given the limitations of our study, a prospective, randomized study looking at Vitamin $\mathrm{C}$ ingestion to reach predefined serum levels is warranted to further investigate the necessary logistics of Vitamin $\mathrm{C}$ use in the prevention of chronic diseases such as diabetes.

Keywords: Diabetes mellitus; Vitamin C; Anti-oxidant

\section{Introduction}

Diabetes mellitus (DM) is one of the most common diseases afflicting the United States (U.S.) population. The American Diabetes Association estimates that $8 \%$ of the U.S. population has been diagnosed with this disease [1]. Furthermore, an additional $20-26 \%$ of the population has so-called "prediabetes", defined as hyperglycemia that does not reach diabetic levels [2]. Thus, approximately one-third of the U.S. population suffers from a syndrome or disease related to elevated serum glucose levels. In light of this growing epidemic, increasing focus is being placed on primary and secondary prevention of diabetes mellitus.

With disease prevention in mind, one area that is receiving increased attention is nutrition management for the prevention of chronic disease. Vitamin C (Ascorbic acid) is considered to be one of the most potent anti-oxidants present in the body. Studies have shown that Vitamin C has protective effects against stroke, hypertension, coronary heart disease and peripheral vascular disease [3-6]. The mechanism by which Vitamin C exerts this protective effect is its uricosuric properties. Since uric acid, a metabolic waste product of the high-fructose, Western diet, is thought to be linked to oxidative damage and felt to be a proximate cause of such conditions as hypertension and diabetes mellitus, the uric acid clearing effects of Vitamin $\mathrm{C}$ are believed to prevent these chronic illnesses [7-9]. To date, research investigating whether increasing one's Vitamin $\mathrm{C}$ ingestion results in a lower risk of diabetes mellitus is scant. Thus, we present 
the results of our epidemiologic analysis of whether Vitamin $\mathrm{C}$ levels are related to the development of diabetes mellitus.

\section{Materials and Methods}

The National Health and Nutrition Examination Survey (NHANES) is a continuous nation-wide research initiative performed on a representative sample of the U.S. population, and is jointly administered by the National Center for Health Statistics and the Centers for Disease Control and Prevention (CDC). This sample is chosen using a stratified, multistage probability cluster sampling design of the non-institutionalized, non-military U.S. population [10]. Components of this survey include questionnaires regarding study subject demographics, health status, in conjunction with performance of general medical examinations; and collection of body fluids for laboratory testing. The physical examination component of NHANES consists of performance of medical and dental exams, and collection anthropometrical measurements by trained personnel [10].

For the purpose of our study, we examined NHANES data collected in 2005 and 2006. Exclusion criteria in our protocol removed all data for NHANES participants who were younger than twenty years or who had missing data values. Of 10,348 participants who had data collected during this two-year period, 4979 did not meet any exclusion criteria, and were included in our data analysis [11]. We divided the Vitamin $\mathrm{C}$ levels into quartiles to ensure good distribution, and for the purpose of dose-effect comparison.

\section{Laboratory methods}

Vitamin C levels in the plasma were measured using isocratic High Performance Liquid Chromatography (HPLC). This utilizes the reaction between trisodium phosphate, dithiothreitol and an internal standard, with the supernatant formed by adding serum plasma to metaphosphoric acid. This solution is filtered and the filtrate is adjusted to a $\mathrm{PH}$ of $3.00 \pm$ 0.03 with various chemicals. Uric acid levels were measured using the LX20 analyser, which utilizes the reaction between uric acid and urecase to produce allantoin and hydrogen peroxide. The hydrogen peroxide produced by the previouslyreferenced reaction is combined with reagents to produce a compound whose intensity in color is proportional to the uric acid level. Fasting glucose measure measurements were performed using a Roche/Hitachi 911 instrument (Roche Diagnostics, Indianapolis, IN), on early morning serum alloquots, collected from study participants who had been observing a nine-hour fast $[10,11]$.

\section{Case definition}

The case definition of diabetes mellitus consisted of a fast- ing blood sugar value of $\geq 126 \mathrm{mg} / \mathrm{dL}$ (7.0 mmol/L), along with affirmative participant responses to any of the following questions: 1) "Other than during pregnancy, have you ever been told by a doctor or other health professional that you have diabetes or sugar diabetes?"; 2) "Are you taking insulin now?"; 3) "Are you taking any pills to decrease your blood sugar?"

\section{Definition of covariables}

The NHANES questionnaire section was used for the definition of age, gender, race, tobacco use pattern, alcohol use, highest level of education achieved, and marital status. Hypertension was defined as a mean systolic blood pressure at or above $140 \mathrm{mmHg}$, a mean diastolic blood pressure at or above $90 \mathrm{mmHg}$, or reporting a physician diagnosis of high blood pressure. Waist circumference below $88 \mathrm{~cm}$ in females and $102 \mathrm{~cm}$ in males, triglyceride levels below $150 \mathrm{mg} / \mathrm{dL}$ and uric acid levels below $7.8 \mathrm{mg} / \mathrm{dL}$ were taken as the reference levels. Body mass index (BMI) was categorized into the follow three groups based on CDC guidelines: normal, overweight, and obese [11].

\section{Statistical analysis}

In order to account for the complex, stratified, multistage probability cluster sampling design employed in the NHANES survey, we analyzed this data using SAS version 9.1's (Cary, North Carolina) Proc Survey methodology [11]. Variance was estimated using the jackknife replacement method. Age-adjusted prevalence estimates were calculated and stratified by demographics and risk factors (Table 1). Furthermore, we used proc survey logistic regression to create a risk-factor based model, and calculated odds ratios with 95\% confidence Intervals. These models were specifically adjusted for age, gender, race, tobacco use, ingestion of alcohol, educational level, hypertension, waist circumference, uric acid levels, triglyceride levels, BMI, and marital status.

\section{Results}

The Vitamin C levels in our study population were normally distributed with a right-sided tail (Fig. 1), with a mean Vitamin $\mathrm{C}$ level of $69 \mathrm{mmol} / \mathrm{L}$. The unadjusted odds ratios of having diabetes in the four quartiles starting from lowest to highest were 1, 0.87 (95\% CI of $0.67-1.13), 0.62$ (95\% CI of $0.50-0.78)$ and 0.45 (95\% CI of $0.359-0.557)$, respectively. When the analysis was adjusted for age, gender, race, tobacco use, alcohol ingestion, education, hypertension, waist circumference, uric acid level, triglyceride levels, BMI and marital status, the odds ratios still showed a dose-response relationship with adjusted odds ratios of $1,0.79(95 \% \mathrm{CI}$ of $0.6-1.04), 0.58(95 \% \mathrm{CI}$ of $0.45-0.76)$ and 0.53 (95\% CI of 
Table 1. Demographic Characteristics of All Four Quartiles of Plasma Vitamin C Levels

\begin{tabular}{|c|c|c|c|c|}
\hline Covariables & $\begin{array}{l}\text { 1st Quartile } \\
\text { Percentage } \\
\text { (standard error) }\end{array}$ & $\begin{array}{l}\text { 2nd Quartile } \\
\text { Percentage } \\
\text { (standard error) }\end{array}$ & $\begin{array}{l}\text { 3rd Quartile } \\
\text { Percentage } \\
\text { (standard error) }\end{array}$ & $\begin{array}{l}\text { 4th Quartile } \\
\text { Percentage } \\
\text { (standard error) }\end{array}$ \\
\hline Age $20-40 y r s$ & $28.30(2.25)$ & $19.45(0.89)$ & $24.63(1.57)$ & $27.62(1.82)$ \\
\hline Age $40-60$ yrs & $31.33(2.07)$ & $17.28(0.94)$ & $22.99(1.62)$ & $28.41(1.43)$ \\
\hline Age $>60 \mathrm{yrs}$ & $24.31(1.48)$ & $11.80(1.07)$ & $18.45(1.37)$ & $45.45(1.32)$ \\
\hline Non Black & $28.66(1.59)$ & $16.17(0.62)$ & $22.30(1.29)$ & $32.87(1.14)$ \\
\hline Black & $27.86(2.10)$ & $22.00(2.01)$ & $24.59(1.31)$ & $25.54(1.93)$ \\
\hline Male & $32.15(1.74)$ & $19.29(1.25)$ & $22.74(1.10)$ & $25.83(1.22)$ \\
\hline Female & $25.24(1.49)$ & $14.58(1.00)$ & $22.41(1.48)$ & $37.77(1.63)$ \\
\hline Less than high school & $35.34(2.11)$ & $18.55(1.16)$ & $20.53(1.61)$ & $25.58(1.47)$ \\
\hline Greater than high school & $27.09(1.35)$ & $16.47(0.78)$ & $23.01(1.21)$ & $33.43(1.16)$ \\
\hline Unmarried & $30.84(1.48)$ & $18.52(1.02)$ & $23.09(1.40)$ & $27.55(0.92)$ \\
\hline Married & $26.88(1.86)$ & $15.61(0.65)$ & $22.18(1.36)$ & $35.33(1.33)$ \\
\hline Income Level Low & $32.49(1.86)$ & $16.51(1.09)$ & $22.22(1.56)$ & $28.78(1.00)$ \\
\hline Income Level Medium & $28.96(2.13)$ & $18.42(0.82)$ & $22.05(1.75)$ & $30.56(2.17)$ \\
\hline Income Level High & $25.59(1.74)$ & $15.87(1.05)$ & $23.42(1.23)$ & $35.12(1.54)$ \\
\hline No Alcohol & $29.78(1.78)$ & $17.63(0.72)$ & $22.89(1.34)$ & $29.70(1.11)$ \\
\hline Moderate or (vere Alcohol) & $24.36(1.55)$ & $14.13(1.09)$ & $21.43(1.14)$ & $40.08(1.58)$ \\
\hline BMI Normal & $25.64(2.18)$ & $13.89(0.98)$ & $19.70(1.90)$ & $40.77(1.54)$ \\
\hline BMI Overweight & $25.49(1.15)$ & $16.55(1.35)$ & $24.35(1.49)$ & $33.71(1.49)$ \\
\hline BMI Obese & $34.45(1.82)$ & $20.10(1.01)$ & $23.84(1.26)$ & $21.62(1.08)$ \\
\hline No Hypertension & $28.27(1.61)$ & $16.67(0.67)$ & $22.96(1.18)$ & $32.10(1.20)$ \\
\hline Hypertension & $30.07(1.62)$ & $17.73(1.53)$ & $20.57(1.84)$ & $31.63(1.52)$ \\
\hline No Diabetes & $27.66(1.52)$ & $16.72(0.58)$ & $22.93(1.19)$ & $32.66(1.15)$ \\
\hline Diabetes & $37.30(1.24)$ & $17.73(1.78)$ & $19.01(1.66)$ & $25.96(2.09)$ \\
\hline $\begin{array}{l}\text { Waist Circumference } \\
\text { Less than } 88 \mathrm{~cm} \text { in females or } 102 \\
\mathrm{~cm} \text { in males }\end{array}$ & $26.82(1.75)$ & $15.89(0.87)$ & $32.29(1.23)$ & $35.00(1.50)$ \\
\hline $\begin{array}{l}\text { Waist Circumference } \\
\text { greater than or equal to } 88 \mathrm{~cm} \text { in } \\
\text { females or } 102 \mathrm{~cm} \text { in males }\end{array}$ & $30.29(1.36)$ & $17.79(1.01)$ & $22.84(1.41)$ & $29.08(0.94)$ \\
\hline $\begin{array}{l}\text { Triglycerides } \\
\text { Less than } 150 \mathrm{mg} / \mathrm{dL}\end{array}$ & $28.41(2.03)$ & $15.74(1.02)$ & 21.71 & $34.14(1.23)$ \\
\hline $\begin{array}{l}\text { Triglycerides } \\
\text { Greater than or equal to } 150 \mathrm{mg} / \\
\mathrm{dL}\end{array}$ & $28.86(1.73)$ & $18.92(1.00)$ & $24.19(1.57)$ & $28.04(1.24)$ \\
\hline $\begin{array}{l}\text { Uric acid } \\
\text { Less than } 7.8 \mathrm{mg} / \mathrm{dL}\end{array}$ & $28.41(2.03)$ & $15.74(1.02)$ & $21.71(1.33)$ & $34.14(1.23)$ \\
\hline $\begin{array}{l}\text { Uric acid } \\
\text { Greater than } 7.8 \mathrm{mg} / \mathrm{dL}\end{array}$ & $34.27(3.41)$ & $21.22(2.82)$ & $27.09(2.05)$ & $17.42(3.05)$ \\
\hline
\end{tabular}




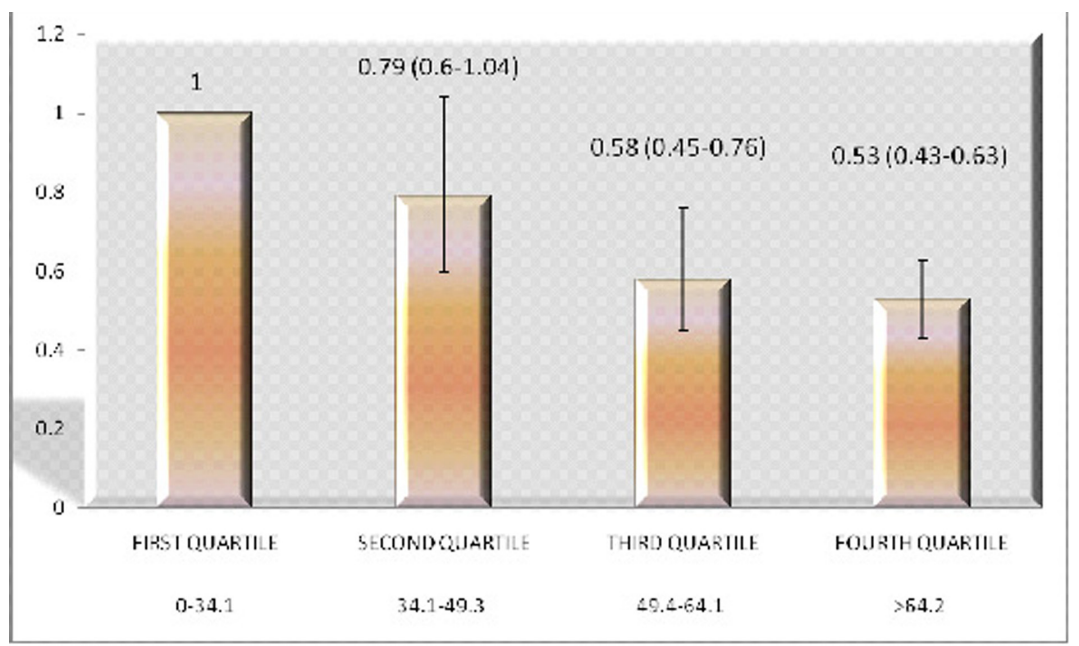

Figure 1. Adjusted odds ratios for having diabetes mellitus with respect to plasma vitamin $\mathrm{C}$ concentration. X Axis: Vitamin C levels in mmol/L; Y Axis: Odds Ratio.

\subsection{3-0.63), respectively (Fig. 1).}

To confirm this association, we divided Vitamin $\mathrm{C}$ levels into 2 groups around a cut-off value of $66 \mathrm{mmol} / \mathrm{L}$. This stratification value has been shown to be appropriate based on prior studies [19]. The adjusted odds ratio in the group with higher serum Vitamin C levels was found to be 0.70 (0.55 to 0.90$)$, with respect to the comparison group (Fig. 2).

\section{Discussion}

Our study supports the hypothesis that higher plasma Vitamin C levels are protective against the development of Diabetes Mellitus. This finding extends the results of previous studies, which have shown a protective effect of Vitamin C with regard to stroke, hypertension, coronary artery disease and peripheral vascular disease [3-6].

In reviewing the pathophysiological rationale for Vitamin C's healthful properties, one quickly comes to realize that the saga of Vitamin C as a medicinal agent is very old, dating back its discovery prophylactic agent against Scurvy [12]. From that time forward, investigation into its various benefits has led to the discovery of its wound healing, tissue repair, and anti-oxidative properties [13, 14]. With specific respect to its anti-oxidative properties, Vitamin C helps to prevent endothelial derangement and initiation of inflammatory responses throughout the body. In discussing mechanisms by which it prevents cardiovascular disease, it has also been conjectured that Vitamin $\mathrm{C}$ degrades oxidized low density lipoproteins (LDL), thus limiting atherosclerosis

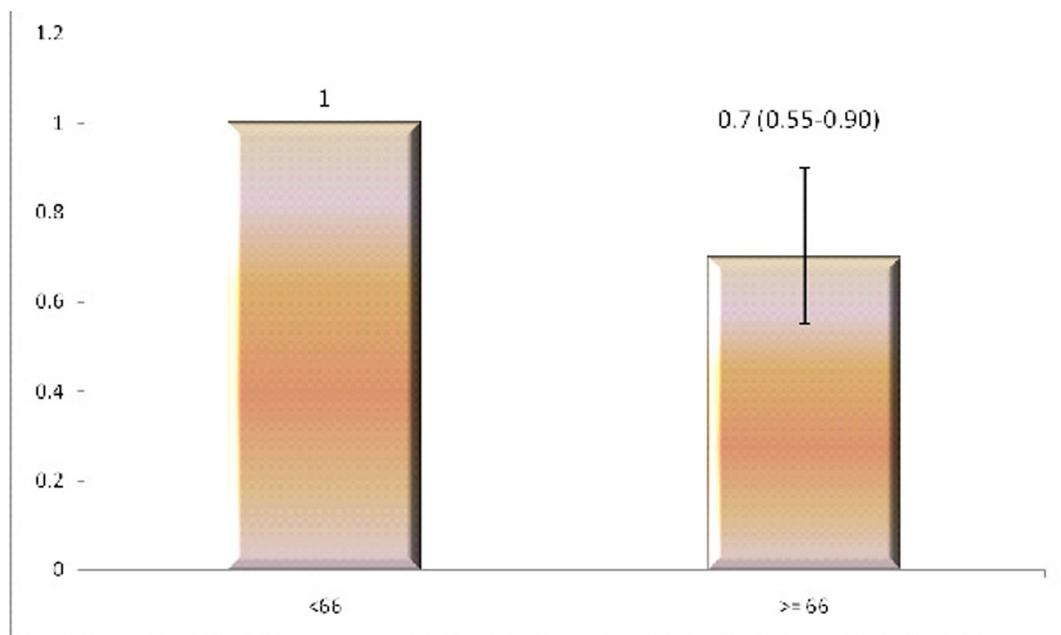

Figure 2. The adjusted odds ratios of having diabetes in two groups based on plasma Vitamin $\mathrm{C}$ levels. X Axis: Vitamin C levels in mmol/L; Y Axis: Odds Ratio. 
at the vascular level [15]. It is interesting to note that, according to Hample et al, $14 \%$ of males and $10 \%$ of females in the U.S. are vitamin C deficient [16]. This finding is all the more curious since Vitamin $\mathrm{C}$ is soluble, and as such can result in limited harm from over- supplementation; increased propensity to kidney stones being the most notable complication.

For this study, we estimated the risk of DM with respect to Vitamin C, by dividing the Vitamin C levels into quartiles. This methodology was employed due to the small number of participants who were identified with DM, in comparison to the total study population. It should be noted that this approach has been validated by further stratifying Vitamin $\mathrm{C}$ levels around a cut point of $66 \mu \mathrm{g} / \mathrm{L}$, and finding a similar association with respect to DM risk. This second investigational strategy is consistent with a methodology utilized in a prior study [17].

In elucidating the inverse association between Vitamin $\mathrm{C}$ and DM, it has been conjectured that Vitamin $\mathrm{C}$ decreases oxidative stress associated with the development of both DM1 and DM2 [18-21]. Furthermore, studies have shown that plasma ascorbic acid levels have an inverse correlation with measured levels of oxidative lymphocytic DNA, which has been conjectured to play a role in the pathogenesis of type 2 diabetes mellitus [22]. In addition, the uricosuric effects of Vitamin C likely play a role in its disease-preventative properties [23]. This assertion is based on contemporary literature which shows a positive correlation between serum uric acid levels and development of Diabetes and Stroke [24, 25].

The results of our study are supported by a small body of literature [25]. However, our study is unique in that we investigated serum Vitamin $\mathrm{C}$ levels, not Vitamin $\mathrm{C}$ ingestion. Thus, gastrointestinal and urinary losses were taken into consideration in our study. As a result, our findings allow for a more direct association between vitamin $\mathrm{C}$ intake and diabetes risk.

One of the many strengths to our study is its large sample size and the ability to generalize our conclusions to the entire U.S. population. We also assessed an extensive array of confounding variables, and have appropriately accounted for them. However, the cross sectional design of this study prevents it from predicting the development of diabetes in subjects with low Vitamin C levels. Also, since study participants were asked to personally fill out questionnaires, misclassification bias may have been introduced into this study. Furthermore, since the NHANES questionnaires did not distinguish between forms of diabetes mellitus, we cannot answer the question of whether the beneficial effects of Vitamin C ingestion translate into lower risk of DM1, DM2, or both. In conclusion, our study suggests that serum Vitamin $\mathrm{C}$ levels are inversely correlated with risk of diabetes mellitus. Given the limitations of our study, a prospective, randomized study looking at Vitamin $\mathrm{C}$ ingestion to reach predefined serum levels is warranted to further investigate the necessary logistics of Vitamin C use in the prevention of chronic diseases such as diabetes.

\section{References}

1. American Diabetes Association. http://www.diabetes. org/diabetes-statistics/prevalence.jsp

2. Cowie CC, Rust KF, Byrd-Holt DD, Eberhardt MS, Flegal KM, Engelgau MM, Saydah SH, et al. Prevalence of diabetes and impaired fasting glucose in adults in the U.S. population: National Health And Nutrition Examination Survey 1999-2002. Diabetes Care. 2006;29(6):1263-1268.

3. Yokoyama T, Date C, Kokubo Y, Yoshiike N, Matsumura $Y$, Tanaka $H$. Serum vitamin $\mathrm{C}$ concentration was inversely associated with subsequent 20 -year incidence of stroke in a Japanese rural community. The Shibata study. Stroke. 2000;31(10):2287-2294.

4. Boekholdt SM, Meuwese MC, Day NE, Luben R, Welch A, Wareham NJ, Khaw KT. Plasma concentrations of ascorbic acid and C-reactive protein, and risk of future coronary artery disease, in apparently healthy men and women: the EPIC-Norfolk prospective population study. Br J Nutr. 2006;96(3):516-522.

5. Langlois M, Duprez D, Delanghe J, De Buyzere M, Clement DL. Serum vitamin C concentration is low in peripheral arterial disease and is associated with inflammation and severity of atherosclerosis. Circulation. 2001;103(14):1863-1868.

6. Duffy SJ, Gokce N, Holbrook M, Huang A, Frei B, Keaney JF, Jr., Vita JA. Treatment of hypertension with ascorbic acid. Lancet. 1999;354(9195):2048-2049.

7. Tuomilehto J, Zimmet P, Wolf E, Taylor R, Ram P, King H. Plasma uric acid level and its association with diabetes mellitus and some biologic parameters in a biracial population of Fiji. Am J Epidemiol. 1988;127(2):321336.

8. Dehghan A, van Hoek M, Sijbrands EJ, Hofman A, Witteman JC. High serum uric acid as a novel risk factor for type 2 diabetes. Diabetes Care. 2008;31(2):361-362.

9. Huang HY, Appel LJ, Choi MJ, Gelber AC, Charleston J, Norkus EP, Miller ER, 3rd. The effects of vitamin C supplementation on serum concentrations of uric acid: results of a randomized controlled trial. Arthritis Rheum. 2005;52(6):1843-1847.

10. Centers for Disease Control and Prevention (CDC). National Center for Health Statistics (NCHS). National Health and Nutrition Examination Survey Data. Hyattsville, MD: U.S. Department of Health and Human Services, Centers for Disease Control and Prevention, [2009][http://www.cdc.gov/nchs/nhanes/nhanes_questionnaires.htm].

11. Centers for Disease Control and Prevention (CDC). 
National Center for Health Statistics (NCHS). National Health and Nutrition Examination Survey Questionnaire (or Examination Protocol, or Laboratory Protocol). Hyattsville, MD: U.S. Department of Health and Human Services, Centers for Disease Control and Prevention, [2009][http://www.cdc.gov/nchs/nhanes/nhanes_questionnaires.htm].

12. Oeffinger KC. Scurvy: more than historical relevance. Am Fam Physician. 1993;48(4):609-613.

13. Carr AC, Frei B. Toward a new recommended dietary allowance for vitamin $\mathrm{C}$ based on antioxidant and health effects in humans. Am J Clin Nutr. 1999;69(6):10861107.

14. Ulrich-Merzenich G, Zeitler H, Panek D, Bokemeyer $\mathrm{D}$, Vetter H. Vitamin $\mathrm{C}$ promotes human endothelial cell growth via the ERK-signaling pathway. Eur J Nutr. 2007;46(2):87-94.

15. Pierdomenico SD, Costantini F, Bucci A, De Cesare D, Cuccurullo F, Mezzetti A. Low-density lipoprotein oxidation and vitamins $\mathrm{E}$ and $\mathrm{C}$ in sustained and white-coat hypertension. Hypertension. 1998;31(2):621-626.

16. Hampl JS, Taylor CA, Johnston CS. Vitamin C deficiency and depletion in the United States: the Third National Health and Nutrition Examination Survey, 1988 to 1994. Am J Public Health. 2004;94(5):870-875.

17. Fletcher AE, Breeze E, Shetty PS. Antioxidant vitamins and mortality in older persons: findings from the nutrition add-on study to the Medical Research Council Trial of Assessment and Management of Older People in the Community. Am J Clin Nutr. 2003;78(5):999-1010.

18. Urakawa H, Katsuki A, Sumida Y, Gabazza EC, Murashima $\mathrm{S}$, Morioka $\mathrm{K}$, Maruyama $\mathrm{N}$, et al. Oxidative stress is associated with adiposity and insulin resistance in men. J Clin Endocrinol Metab. 2003;88(10):46734676.

19. Perticone F, Ceravolo R, Candigliota M, Ventura G, Iacopino S, Sinopoli F, Mattioli PL. Obesity and body fat distribution induce endothelial dysfunction by oxidative stress: protective effect of vitamin C. Diabetes. 2001;50(1):159-165.

20. Atkinson MA, Eisenbarth GS. Type 1 diabetes: new perspectives on disease pathogenesis and treatment. Lancet. 2001;358(9277):221-229.

21. Chan JM, Rimm EB, Colditz GA, Stampfer MJ, Willett WC. Obesity, fat distribution, and weight gain as risk factors for clinical diabetes in men. Diabetes Care. 1994;17(9):961-969.

22. Patti ME, Butte AJ, Crunkhorn S, Cusi K, Berria R, Kashyap S, Miyazaki Y, et al. Coordinated reduction of genes of oxidative metabolism in humans with insulin resistance and diabetes: Potential role of PGC1 and NRF1. Proc Natl Acad Sci U S A. 2003;100(14):8466-8471.

23. Choi SW, Benzie IF, Lam CS, Chat SW, Lam J, Yiu CH, Kwan JJ, et al. Inter-relationships between DNA damage, ascorbic acid and glycaemic control in Type 2 diabetes mellitus. Diabet Med. 2005;22(10):1347-1353.

24. Lehto S, Niskanen L, Ronnemaa T, Laakso M. Serum uric acid is a strong predictor of stroke in patients with non-insulin-dependent diabetes mellitus. Stroke. 1998;29(3):635-639.

25. Will JC, Ford ES, Bowman BA. Serum vitamin C concentrations and diabetes: findings from the Third National Health and Nutrition Examination Survey, 19881994. Am J Clin Nutr. 1999;70(1):49-52. 